\title{
Oxytocin bolus versus oxytocin bolus and infusion for control of blood loss at elective caesarean section: double blind, placebo controlled, randomised trial
}

\author{
Sharon $\mathrm{R}$ Sheehan research fellow in obstetrics ${ }^{1}$, Alan A Montgomery reader in health services \\ research ${ }^{2}$, Michael Carey director of anaesthetics and perioperative medicine ${ }^{3}$, Fionnuala M McAuliffe \\ associate professor of obstetrics and gynaecology ${ }^{4}$, Maeve Eogan consultant obstetrician and \\ gynaecologist ${ }^{5}$, Ronan Gleeson consultant obstetrician and gynaecologist ${ }^{56}$, Michael Geary \\ consultant obstetrician and gynaecologist ${ }^{5}$, Deirdre $\mathrm{J}$ Murphy professor of obstetrics and head of \\ department ${ }^{1}$, The ECSSIT Study Group
}

\begin{abstract}
${ }^{1}$ Academic Department of Obstetrics and Gynaecology, Trinity College Dublin, Coombe Women and Infants University Hospital, Dublin 8, Ireland; ${ }^{2}$ School of Social and Community Medicine, University of Bristol, Canynge Hall, Bristol, UK; ${ }^{3} \mathrm{Coombe}$ Women and Infants University Hospital; ${ }^{4}$ Department of Obstetrics and Gynaecology, University College Dublin, National Maternity Hospital, Dublin ; ${ }^{5}$ Rotunda Hospital, Dublin; ${ }^{6}$ Trinity
\end{abstract} College Dublin

\begin{abstract}
Objectives To determine the effects of adding an oxytocin infusion to bolus oxytocin on blood loss at elective caesarean section.

Design Double blind, placebo controlled, randomised trial, conducted from February 2008 to June 2010.

Setting Five maternity hospitals in the Republic of Ireland.

Participants 2069 women booked for elective caesarean section at term with a singleton pregnancy. We excluded women with placenta praevia, thrombocytopenia, coagulopathies, previous major obstetric haemorrhage (>1000 $\mathrm{mL}$ ), or known fibroids; women receiving anticoagulant treatment; those who did not understand English; and those who were younger than 18 years.

Intervention Intervention group: intravenous slow $5 \mathrm{IU}$ oxytocin bolus over 1 minute and additional $40 \mathrm{IU}$ oxytocin infusion in $500 \mathrm{~mL}$ of $0.9 \%$ saline solution over 4 hours (bolus and infusion). Placebo group: $5 \mathrm{IU}$ oxytocin bolus over 1 minute and $500 \mathrm{~mL}$ of $0.9 \%$ saline solution over 4 hours (placebo infusion) (bolus only).
\end{abstract}

Main outcomes Major obstetric haemorrhage (blood loss $>1000 \mathrm{~mL}$ ) and need for an additional uterotonic agent.

Results We found no difference in the occurrence of major obstetric haemorrhage between the groups (bolus and infusion 15.7\% (158/1007) $v$ bolus only $16.0 \%$ (159/994), adjusted odds ratio $0.98,95 \%$ confidence intervals 0.77 to $1.25, \mathrm{P}=0.86)$. The need for an additional uterotonic agent in the bolus and infusion group was lower than that in the bolus only group (12.2\% (126/1033) $v 18.4 \%$ (189/1025), $0.61,0.48$ to 0.78 , $\mathrm{P}<0.001)$. Women were less likely to have a major obstetric haemorrhage in the bolus and infusion group than in the bolus only group if the obstetrician was junior rather than senior $(0.57,0.35$ to $0.92, \mathrm{P}=0.02)$.

Conclusion The addition of an oxytocin infusion after caesarean delivery reduces the need for additional uterotonic agents but does not affect the overall occurrence of major obstetric haemorrhage.

Trial Registration Current Controlled Trials ISRCTN17813715.

\section{Introduction}

Caesarean section is one of the most commonly performed major operations in women throughout the world. These operations have escalated over the past four decades to between $20 \%$ and $30 \%$ in most developed countries, up to $40 \%$ in China, and as high as $70 \%$ in some Latin American countries. ${ }^{1-3}$ Operative morbidity includes haemorrhage, anaemia, risks of transfusion, hysterectomy, and in severe cases, maternal death. ${ }^{4}$ Obstetric haemorrhage is the leading cause of maternal mortality worldwide, and in most cases it relates to uterine atony.

Although the value of routine oxytocics to reduce postpartum haemorrhage after vaginal birth has been well established, their value in caesarean section has received little attention. ${ }^{5}$ It has been assumed that the benefits of oxytocics observed at vaginal birth also apply to caesarean section. ${ }^{67}$ The guidelines of the Royal College of Obstetricians and Gynaecologists (UK) on caesarean section recommend a slow intravenous bolus dose of $5 \mathrm{IU}$ of oxytocin after delivery of the infant. ${ }^{8}$ This dose is based on the principles of active management of the third stage of labour ${ }^{910}$ and is consistent with practice across most of Europe and Australia. ${ }^{11}$ In a survey of obstetricians and anaesthetists in 
the UK, the use of an oxytocin bolus was standard treatment, although the dose varied between $5 \mathrm{IU}$ and $10 \mathrm{IU} .{ }^{12}$ In settings where an oxytocin bolus is used routinely, an additional infusion of oxytocin may be required if haemorrhage occurs. This practice has led some obstetricians to use an additional infusion of oxytocin on a selective or routine basis for high risk cases, despite a lack of evidence to support this practice. ${ }^{12} 13$

By contrast, an alternative practice in the United States recommends the use of an oxytocin infusion instead of a bolus dose. This approach may reflect concerns about the physiological effects of bolus oxytocin. ${ }^{14}$ Intravenous oxytocin has a short half life (4-10 minutes); therefore the potential advantage of an oxytocin infusion at caesarean section is in maintaining uterine contractility throughout the surgical procedure and immediate postpartum period, when most primary haemorrhage occurs. Various newer uterotonic agents have been evaluated, ${ }^{15-20}$ and the recent Canadian guidelines recommend the use of carbetocin (a long acting synthetic oxytocic) instead of oxytocin at caesarean section. ${ }^{21}$ However, carbetocin is expensive and would not be available in settings where resources are scarce.

We aimed to compare a standard 5 IU bolus of oxytocin and an additional 40 IU oxytocin infusion (bolus and infusion) with a 5 IU bolus of oxytocin and placebo infusion (bolus only), to determine whether use of an inexpensive and widely used drug can further improve prevention of haemorrhage at caesarean section. We postulated that a routine additional oxytocin infusion would reduce either the occurrence of major obstetric haemorrhage or the use of an additional uterotonic agent by preventing uterine atony.

\section{Methods}

The Elective Caesarean Section Syntocinon (oxytocin) Infusion Trial (ECSSIT) was a double blind, placebo controlled, randomised study.

\section{Population}

The study population included healthy women at term ( $>36$ weeks) with singleton pregnancies booked for elective caesarean section. We excluded women with placenta praevia, thrombocytopenia, coagulopathies, previous major obstetric haemorrhage $(>1000 \mathrm{~mL})$, known fibroids, or women who received anticoagulant treatment. We also excluded women who did not understand English or were younger than 18 years. Clinicians could exclude additional patients at their discretion if they expected major haemorrhage, in keeping with the recommendations of the research ethics committee.

\section{Intervention and comparison}

We compared oxytocin bolus $5 \mathrm{IU}$ and oxytocin infusion (40 IU oxytocin in $500 \mathrm{~mL}$ saline infused over four hours) with 5 IU oxy tocin bolus and placebo infusion $(500 \mathrm{~mL}$ saline infused over 4 hours).

\section{Outcomes}

\section{Primary outcomes}

There were two primary outcomes, both of which were binary: major obstetric haemorrhage and use of an additional uterotonic agent. We defined major obstetric haemorrhage as calculated blood loss of more than $1000 \mathrm{~mL}$. This estimate was based on the difference between the preoperative and postoperative packed cell volume (PCV), and is calculated as follows: ${ }^{22}{ }^{23}$

\section{Calculated estimated blood loss $=$ estimated blood volume $\times$ (preoperative PCV - postoperative $\mathrm{PCV}) /$ preoperative PCV \\ (where estimated blood volume $=$ booking weight $(\mathrm{kg})$ $\times 85)$}

We chose this calculation as a quantitative objective measure to estimate haemorrhage because it is widely accepted that clinicians underestimate blood loss and that gravimetric methods include liquor in addition to blood, which limits accuracy. ${ }^{24} \mathrm{We}$ chose the use of an additional uterotonic agent as a primary outcome because obstetricians are likely to intervene in the event of uterine atony and use an additional agent to prevent haemorrhage.

\section{Secondary outcomes}

We assessed blood loss gravimetrically by measuring the suction volume and swab weight to establish a "measured" blood loss. We used disposable waterproof drapes with pockets that captured blood and liquor. Although this approach is subject to technical and observer error, it is considered more accurate than clinicians' subjective estimations of blood loss. Additionally, routine preoperative and postoperative measurement of packed cell volume is not performed in many countries. Other secondary outcomes included: change in haemoglobin and packed cell volume; severe anaemia 48 hours after delivery (reduction in haemoglobin $\geq 20 \%$ ); need for blood transfusion; side effects (including vomiting and hypotension); and postnatal length of stay in theatre or recovery and in hospital.

\section{Trial procedures}

We undertook an initial pilot study to inform the design of the main trial, the recruitment procedures, and the sample size calculation. ${ }^{25}$ We recruited women from four university teaching hospitals and one private hospital in the Republic of Ireland between February 2008 and June 2010. Eligible women were approached and offered study information at the time of booking for elective caesarean section. On the day of surgery, the women confirmed participation and completed informed written consent.

Randomisation took place after patients consented to participation in the study. We used an automated web based randomisation system ensuring allocation concealment. Allocation was stratified by centre and previous caesarean section (no/yes), and blocked by use of random permuted blocks of varying size. We randomly assigned women to receive either an intravenous slow bolus of oxytocin $5 \mathrm{IU}$ over 1 minute and $40 \mathrm{IU}$ oxytocin in $500 \mathrm{~mL}$ of $0.9 \%$ saline solution over 4 hours (bolus and infusion), or an oxytocin bolus 5 IU over 1 minute and $500 \mathrm{~mL}$ of $0.9 \%$ saline solution over 4 hours (bolus only). A clinically trained researcher (midwife or obstetric research fellow) prepared the active and placebo infusions away from the theatre. This process ensured the blinding of everyone except for this individual, who then had no subsequent role in patient management or outcome assessment.

We defined the grade of obstetrician or anaesthetist as junior and senior, with a junior individual having had specialist training for three years or less. Surgical and anaesthetic techniques were standardised, with all patients undergoing spinal anaesthesia. Patients received an intravenous bolus of $500 \mathrm{~mL}$ crystalloid before spinal anaesthesia. Anaesthetists replaced blood loss at operation with colloid infusion or blood when deemed necessary. Intravenous crystalloids were continued at 1 L every 8 hours until the morning after surgery, unless the patient was unable to tolerate oral fluids. Surgeons operated to a standard procedure 
that specified controlled cord traction for delivery of the placenta after administration of the oxytocin bolus, two layer closure of the uterine incision, and to avoid delivering the uterus for suturing unless clinically indicated. If the uterus remained atonic despite the trial intervention, the obstetrician or anaesthetist could use an additional uterotonic agent by replacing the trial infusion with a known oxytocin infusion or by using other additional agents (or both). We recorded deviations from these standard procedures. The published trial protocol provides further details. ${ }^{26}$

The trial steering committee met quarterly. An independent data monitoring committee reviewed recruitment and safety data after recruitment of 1000 patients.

We received institutional ethics approval and maternal written consent.

\section{Statistical analysis}

We estimated from our pilot study that around $14 \%$ of study participants in the bolus only group would have a blood loss of greater than $1000 \mathrm{~mL}$, and that a relative reduction of $20-50 \%$ would be feasible and clinically important. ${ }^{25}$ With an estimated incidence in the bolus only group of $14 \%, 80 \%$ power, and $5 \%$ two sided $\alpha$, a total number for analysis of 1000 participants per group would be required to detect a between group difference of 4.2 percentage points, equivalent to an odds ratio of 0.67. We inflated the target sample size to be recruited, to allow for a $3 \%$ margin of missing primary outcome data (for example, blood test not performed or at the wrong time point). Analysis was by intention to treat.

We evaluated the success of blinding within a subsample of 109 recruited patients by asking patients, obstetricians, and anaesthetists to identify the infusion (327 responses). Our analysis used Cohen's $\kappa$ coefficient, which examines the level of agreement beyond that expected by chance. Agreement ranges from " $<0$ ", implying no agreement, to " $>0.81$ ", indicating almost perfect agreement. All analyses were blinded to treatment allocation using SPSS 16 and Stata 11.

We used descriptive statistics to assess comparability of the trial groups at baseline. The primary between group comparisons for both primary (binary) outcomes used multivariable logistic regression models with adjustment for stratification variables. We then investigated the effects on the primary analyses of further adjustment for any variables displaying a noticeable imbalance between the groups at baseline. We analysed secondary outcomes in a similar way using regression models (logistic or linear) depending on outcome type. Results from all regression models are presented as point estimates (odds ratios or differences in means), 95\% confidence intervals, and $\mathrm{P}$ values. Finally we conducted a series of planned subgroup analyses by including appropriate interaction terms in the regression models to ascertain any differential effects in relation to operator experience (junior or senior grade), choice of anaesthetic (adherence or non-adherence to protocol), and repeat caesarean section $(0,1, \geq 2){ }^{26}$

\section{Results}

\section{Study population}

We enrolled 2069 women, of whom 2058 were suitable for inclusion ( 1025 bolus only, 1033 bolus and infusion). We deemed 11 women to be ineligible after randomisation because their caesarean sections were cancelled. Participant flow is shown in figure 1. Patients were followed up until hospital discharge.

\section{Descriptive statistics}

Table 1 lists characteristics of the trial participants at baseline. The mean age of women at delivery was 33.2 years, the median parity was 1 (interquartile range 1). Of the 2058 eligible women, $712(34.6 \%)$ had no previous caesarean section and 1943 $(94.4 \%)$ received the intervention as intended. For women who had preoperative haemoglobin concentrations recorded, the occurrence of preoperative anaemia (haemoglobin $<105.0 \mathrm{~g} / \mathrm{L}$ ) was high (14.7\% (302/2053)). Junior obstetricians performed $42.1 \%(866 / 2058)$ of the caesarean sections. Women and clinicians were successfully blinded to treatment allocation, with neither group able to identify the trial infusion with any accuracy beyond chance (overall 207 did not know, 62 were correct, 47 were incorrect, 11 had no response; $\kappa=0.15$ ).

\section{Primary outcomes}

Primary outcome data were collected for 2001 (97\%) participants for major obstetric haemorrhage, and for 2058 (100\%) participants for the use of an additional uterotonic agent. Almost one in six women in the study had a major obstetric haemorrhage, with a similar proportion requiring an additional uterotonic agent (table 2). There was no difference in major obstetric haemorrhage between the groups (bolus and infusion $15.7 \%, 158 / 1007 v$ bolus only $16.0 \%, 159 / 994$, adjusted odds ratio $0.98,95 \%$ confidence intervals 0.77 to $1.25, \mathrm{P}=0.86$ ). Women in the bolus and infusion group were less likely to require an additional uterotonic agent than those in the bolus only group $(12.2 \%, 126 / 1033 v 18.4 \%, 189 / 1025,0.61,0.48$ to $0.78, \mathrm{P}<0.001)$. A known oxytocin infusion was the most commonly chosen additional uterotonic agent used (13.4\%, 276/2058). Other uterotonics used included misoprostol (4.7\%, $96 / 2058)$, oxytocin bolus $(1.0 \%, 20 / 2058)$,

15-methyl-prostaglandin $\mathrm{F}_{2 \alpha}(0.5 \%, 10 / 2058)$, syntometrine $(0.4 \%, 8 / 2058)$, and ergometrine $(0.3 \%, 7 / 2058)$.

\section{Secondary outcomes}

We found no difference in any of the secondary outcomes between the two groups (table 3). Occurrence of postoperative anaemia (haemoglobin $<100.0 \mathrm{~g} / \mathrm{L})$ and severe anaemia $(\geq 20 \%$ fall in haemoglobin) were high overall, but did not differ between the groups. The allocated trial infusion was discontinued in 216 women $(10.5 \%) ; 87$ (8.4\%) in the bolus and infusion group and $129(12.6 \%)$ in the bolus only group $(\mathrm{P}=0.002)$, mostly for increased bleeding $(39 \%, 84 / 216)$ and uterine atony $(36 \%, 78 / 216)$.

\section{Subgroup analyses}

Major obstetric haemorrhage occurred more frequently in women delivered by junior obstetricians than by senior obstetricians $(19.6 \%, 164 / 835 v 13.1 \%, 153 / 1166)$. Women were less likely to have a major obstetric haemorrhage in the bolus and infusion group than in the bolus only group if the obstetrician was junior rather than senior (odds ratio $0.57,95 \%$ confidence intervals 0.35 to $0.92, \mathrm{P}=0.02$ ) (table 4 ). The effects of bolus and infusion on either primary outcome did not differ for any of the other subgroup variables investigated.

Despite the imbalance in adherence to surgical protocol between the two groups, it did not affect the occurrence of major obstetric haemorrhage (odds ratio $0.81,95 \%$ confidence intervals 0.46 to $1.44, \mathrm{P}=0.48$ ) or the need for an additional uterotonic agent (1.16, 0.63 to $2.15, \mathrm{P}=0.63)$. 


\section{Discussion}

In this large multicentre trial of women delivered by elective caesarean section, we found that an oxytocin infusion in addition to an oxytocin bolus had no effect on overall occurrence of major obstetric haemorrhage compared with an oxytocin bolus and placebo infusion. However, an additional infusion of oxytocin did reduce the need for another uterotonic agent. Major obstetric haemorrhage was reduced after use of oxytocin bolus and oxytocin infusion at caesarean section by junior obstetricians compared with senior obstetricians. Use of an oxytocin infusion after an initial bolus did not increase the occurrence of side effects.

\section{Strengths and limitations}

We conducted a large pragmatic clinical trial within five maternity centres in the Republic of Ireland. We defined the population carefully, with a range of indications for caesarean section and varying grades of operator. The results are generalisable to similar populations. Surgical techniques and anaesthesia were standardised. Data were collected by trained staff with theatre staff appropriately trained in the measurement of blood loss. Packed cell volumes were checked at 48 hours after delivery to provide an adequate interval for haemodynamic equilibrium.

Some limitations of our study warrant consideration. Arguably, we should have included a third comparison group that reflected current US clinical practice-use of a placebo bolus with an oxytocin infusion (infusion only). However, this additional group would have required a deviation from hospital protocols based on recommendations by the Royal College of Obstetricians and Gynaecologists. ${ }^{8}$ Although we considered this approach, we thought that it would not have been acceptable in any of our recruitment centres, where oxytocin bolus is standard practice. ${ }^{22} \mathrm{We}$ chose to follow the UK guidelines, basing our decision on the benefits described in vaginal birth where a bolus dose of oxytocin has a proved role in prevention of postpartum haemorrhage. ${ }^{910}$ The mechanisms of action of oxytocin bolus and infusion are thought to differ; a bolus causes constriction of the venous sinuses, leading to placental separation and placental bed haemostasis, whereas an infusion maintains uterine contractility.

We debated the choice of primary outcome and decided on two outcomes, both reflecting uterine atony. Major obstetric haemorrhage is the most relevant clinical outcome because it is a leading cause of maternal death worldwide. However, clinicians intervene in the event of uterine atony by administering an additional uterotonic agent. In itself, this intervention would be an important outcome. We measured total blood loss at the time of caesarean section but chose a calculation based estimate, based on preoperative and postoperative packed cell volume as a primary outcome in the interests of objectivity. The measured blood loss would be more relevant in resource poor settings where blood tests are not routinely performed.

\section{Comparison with existing literature}

One trial compared the use of oxytocin bolus and placebo infusion with oxytocin bolus and $30 \mathrm{IU}$ oxytocin infusion. ${ }^{27}$ Data showed reductions in both the use of additional uterotonic agents and major obstetric haemorrhage. However, these results are not generalisable because all caesarean sections were performed in a military hospital setting with routine general anaesthesia. Regional anaesthetic techniques are standard at elective caesarean section in developed countries and the use of general anaesthesia is uncommon. General anaesthesia is known to increase blood loss at the time of caesarean section as inhalational agents can reduce uterine contractility and increase atony. ${ }^{28} 29$

Another small trial investigated the effects of a placebo bolus and oxytocin infusion compared with an oxytocin bolus and oxytocin infusion, and found no difference in the need for an additional uterotonic agent in the first 24 hours after caesarean section. ${ }^{30}$ However, this trial is relevant to US practice but not to European practice and it was limited to patients at high risk of uterine atony, with neither surgery nor anaesthesia standardised and blood loss estimated visually. By contrast, we examined a very large sample of women undergoing elective caesarean section with regional anaesthesia and our results are more relevant to the general obstetric population.

Carbetocin is a synthetic oxytocin agonist that has a longer half life than oxytocin and could be of value. A trial comparing oxytocin 5 IU bolus versus carbetocin $100 \mu \mathrm{g}$ showed an increased use of additional uterotonic agents in the oxytocin arm. ${ }^{20}$ As in our trial, there was no change in mean blood loss between the two groups. The high cost of carbetocin will prevent its use in countries where resources are scarce and indeed even in developed countries that implement cost cutting measures.

\section{Clinical implications}

We reported a high occurrence of major obstetric haemorrhage, greater than that reported in previous studies. ${ }^{31}{ }^{32}$ However, the different methods of estimating blood loss limits direct comparisons with other studies. ${ }^{33}$ Although estimation of blood loss at caesarean section can be imprecise, major obstetric haemorrhage is common, even in women who seem at low risk. This observation leads us to question whether a woman undergoing an elective caesarean section can ever really be defined as being at low risk. Vigilance in monitoring blood loss and prompt management are essential to avoid the associated morbidity and mortality.

Although we found a reduction in the use of additional uterotonic agents, but no change in overall occurrence of major obstetric haemorrhage with use of oxytocin bolus and infusion, we did show a reduced occurrence of major obstetric haemorrhage among inexperienced operators. In our trial, we had a relatively high proportion of experienced operators reflecting private practice in Ireland. The proportion of inexperienced operators will be higher in UK training hospitals and certainly in parts of the world where access to trained staff is restricted.

We need to consider how our findings could be implemented. One approach would be to recommend that all women undergoing elective caesarean section should receive an oxytocin bolus and infusion. This approach would eliminate the need for clinical judgment on when to use an additional uterotonic agent. The potential downside would be that some women would receive an unnecessary infusion. Alternatively, a more selective approach might be to recommend oxytocin infusions at all elective caesarean sections performed by inexperienced operators, whose judgment of when to use additional uterotonic agents may not be as reliable.

While the rates of caesarean section continue to escalate, future research aimed at reducing major obstetric haemorrhage and haemorrhagic complications is essential. Previous work has shown that the risk of major obstetric haemorrhage is greater at emergency than at elective caesarean section. ${ }^{31}$ Our study was limited to women undergoing elective caesarean section; future work should address non-elective deliveries. We are planning 
further work on the cost effectiveness of the introduction of an additional oxytocin infusion at elective caesarean section. Oxytocin is an inexpensive drug but infusions require either a 4 hour period of monitoring or the use of a controlled infusion pump. Although 4 hours' observation after a caesarean section is in the patient's best interests, the delay in transferring patients to the postnatal ward affects case throughput. This additional step would need to be balanced with the risk of an unrecognised postpartum haemorrhage occurring on the ward.

\section{Conclusions}

Our findings show that the addition of an oxytocin infusion at elective caesarean section significantly reduces the need for an additional uterotonic agent, although it does not reduce overall rates of major obstetric haemorrhage. An oxytocin infusion is an inexpensive, well tolerated, and relatively safe medication which, when used routinely, avoids the uncertainty of which patients should receive an additional uterotonic agent. Our findings support the use of an additional oxytocin infusion in terms of reducing major obstetric haemorrhage where the operator is inexperienced and this approach could be implemented safely and cheaply into current clinical practice.

We thank all the women who took part in the study and also the hospitals and research staff involved. We thank our research midwives, Ann Marie Connor, Michelle D’Arcy, Clare Dunney, Hilary Gilligan, Ruth O'Connor, and Eleanor Woods; the pharmacy staff of each hospital; the consultant leads for the trial in each hospital, Ronan Gleeson (Rotunda Hospital, Dublin), Fionnuala McAuliffe (National Maternity Hospital, Dublin), Deirdre Murphy (Coombe Women and Infants University Hospital, Dublin), Valerie Donnelly (Mount Carmel Hospital, Dublin), and Seosamh O Coigligh (Our Lady of Lourdes Hospital, Drogheda); and the masters of the Dublin maternity hospitals, Chris Fitzpatrick, Michael Geary, and Michael Robson. We appreciate the assistance of Sharon Cooley and Hassan Rajab with the early stages of recruitment, and Patricia Crowley for support throughout the trial. We also acknowledge the support of our data monitoring and ethics committee, Andrew Weeks (chair), Louise Kenny, and Ed Juszczak; and the independent chair of the trial steering committee, Bryony Strachan. We are very grateful to the editorial committee and the peer reviewers for their very helpful comments.

Funding: The trial was funded by the Health Research Board of Ireland (RP/2007/171), with additional financial support from the Coombe Women and Infants University Hospital, Dublin. None of the funding sources had a role in the trial design, writing of the report, or the decision to submit the paper for publication.

Competing interests: No competing interests declared. All authors have completed the Unified Competing Interest form at http://www.icmje.org/ coi_disclosure.pdf (available on request from the corresponding author) and declare: no support from any organisation for the submitted work (apart from the funding described by the Health Research Board of Ireland and the Coombe Women and Infants University Hospital); no financial relationships with any organisations that might have an interest in the submitted work in the previous three years; no other relationships or activities that could appear to have influenced the submitted work.

Ethical approval: We received institutional ethics approval and participants provided written consent.

Contributors: DJM had the original idea for the study. DJM, SRS, AAM, MC, FMMcA, ME, RG, and MG designed the study. DJM, AAM, and $M C$ obtained funding. SRS and AAM carried out the analysis. SRS drafted the manuscript, which was revised by all authors. DJM is the guarantor.

Data sharing: No additional data available.

Martin JA, Hamilton BE, Sutton PD, Ventura MA, Mathews TJ, Kirmeyer S, et al. Births: final data for 2007. Natl Vital Stat Rep 2010;58:24.
2 Thomas J, Paranjothy S, Royal College of Obstetricians and Gynaecologists Clinical Effectiveness Support Unit. National sentinel caesarean section audit report. Royal College of Obstetricians and Gynaecologists, 2001.

3 Cai WW, Marks JS, Chen CH, Zhuang YX, Morris L, Harris JR. Increased cesarean section rates and emerging patterns of health insurance in Shanghai, China. Am J Public Health 1998;88:777-80.

4 Lewis $\mathrm{G}$, editor). The confidential enquiry into maternal and child health (CEMACH). Saving mothers' lives: reviewing maternal deaths to make motherhood safer-2003-2005. CEMACH, 2007.

5 Elbourne DR, Prendiville WJ, Carroli G, Wood J, McDonald S. Prophylactic use of oxytocin in the third stage of labour. Cochrane Database Syst Rev 2001;4:CD001808.

6 Lokugamage AU, Paine M, Bassaw Balroop K, Sullivan KR, Refaey HE, Rodeck CH. Active management of the third stage at caesarean section: a randomised controlled trial of misoprostol versus syntocinon. Aust N Z J Obstet Gynaecol 2001:41:411-4.

7 Munn MB, Owen J, Vincent R, Wakefield M, Chestnut DH, Hauth JC. Comparison of two oxytocin regimens to prevent uterine atony at cesarean delivery: a randomized controlled trial. Obstet Gynecol 2001;98:386-90.

8 National Collaborating Centre for Women's and Children's Health. Caesarean section. Clinical guideline. RCOG Press, 2004.

9 Cotter A, Ness A, Tolosa J. Prophylactic oxytocin for the third stage of labour. Cochrane Database Syst Rev 2001;4:CD001808.

10 Begley CM, Gyte GM, Murphy DJ, Devane D, McDonald SJ, McGuire W. Active versus expectant management for women in the third stage of labour. Cochrane Database Syst Rev 2010;7:CD007412.

11 Mockler JC, Murphy DJ, Wallace EM. An Australian and New Zealand survey of practice of the use of oxytocin at elective caesarean section. Aust N Z J Obstet Gynaecol 2010:50:30-5.

12 Wedisinghe L, Macleod M, Murphy DJ. Use of oxytocin to prevent haemorrhage at caesarean section-a survey of practice in the United Kingdom. Eur J Obstet Gynecol Reprod Biol 2008;137:27-30.

13 Sheehan SR, Wedisinghe L, Macleod M, Murphy DJ. Implementation of guidelines on oxytocin use at caesarean section: a survey of practice in Great Britain and Ireland. Eur J Obstet Gynecol Reprod Biol 2010;148:121-4.

14 ACOG. Practice bulletin: clinical management guidelines for obstetrician-gynaecologists. Number 76. Postpartum hemorrhage. Obstet Gynecol 2006;108:1039-47.

15 Chou MM, MacKenzie IZ. A prospective, double-blind, randomized comparison of prophylactic intramyometrial 15-methyl prostaglandin F2 alpha, 125 micrograms, and intravenous oxytocin, 20 units, for the control of blood loss at elective cesarean section. Am J Obstet Gynecol 1994:171:1356-60.

16 Boucher M, Horbay GLA, Griffin P, Deschamps Y, Desjardins C, Schulz M, et al. Double-blind, randomized comparison of the effect of carbetocin and oxytocin on intraoperative blood loss and uterine tone of patients undergoing cesarean section. $J$ Perinatol 1998;18:202-7.

17 Dansereau J, Joshi AK, Helewa ME, Doran TA, Lange IR, Luther ER, et al. Double-blind comparison of carbetocin versus oxytocin in prevention of uterine atony after cesarean section. Am J Obstet Gynecol 1999;180:670-6.

18 Acharya G, Al-Sammarai MT, Patel N, Al-Habib A, Kiserud T. A randomized, controlled trial comparing effect of oral misoprostol and intravenous syntocinon on intra-operative blood loss during cesarean section. Acta Obstet Gynecol Scand 2001;80:245-50.

19 Eftekhari N, Doroodian M, Lashkarizadeh R. The effect of sublingual misoprostol versus intravenous oxytocin in reducing bleeding after caesarean section. J Obstet Gynaecol 2009:29:633-6.

20 Attilakos G, Psaroudakis D, Ash J, Buchanan R, Winter C, Donald F, et al. Carbetocin versus oxytocin for the prevention of postpartum haemorrhage following caesarean section: the results of a double-blind randomised trial. BJOG 2010;117:929-36.

21 Leduc D, Senikas V, Lalonde AB, Ballerman C, Biringer A, Delaney M, et al. Active management of the third stage of labour: prevention and treatment of postpartum hemorrhage. JOGC 2009;31:980-93.

22 Carvalho JC, Balki M, Kingdom J, Windrim R. Oxytocin requirements at elective cesarean delivery: a dose-finding study. Obstet Gynecol 2004;104:1005-10.

23 Shook PR, Schultz JR, Reynolds JD, Spahn TE, DeBalli P. Estimating blood loss for cesarean section: how accurate are we? Anesthesiology 2003;98:1.

24 Bose $\mathrm{P}$, Regan F, Paterson-Brown S. Improving the accuracy of estimated blood loss at obstetric haemorrhage using clinical reconstructions. BJOG 2006;113:919-24.

25 Murphy DJ, MacGregor H, Munishankar B, McLeod G. A randomised controlled trial of oxytocin $5 I U$ and placebo infusion versus oxytocin $5 I U$ and $30 I U$ infusion for the control of blood loss at elective caesarean section-pilot study. ISRCTN 40302163. Eur J Obstet Gynecol Reprod Biol 2009;142:30-3.

26 Murphy DJ, Carey M, Montgomery AA, Sheehan SR. Study protocol. ECSSIT-Elective Caesarean Section Syntocinon Infusion Trial. A multi-centre randomised controlled trial of oxytocin (Syntocinon) $5 \mathrm{IU}$ bolus and placebo infusion versus oxytocin $5 \mathrm{IU}$ bolus and $40 \mathrm{IU}$ infusion for the control of blood loss at elective caesarean section. BMC Pregnancy Childbirth 2009;9:36.

27 Gungorduk K, Asicioglu O, Celikkol O, Olgac Y, Ark C. Use of additional oxytocin to reduce blood loss at elective caesarean section: a randomised control trial. Aust $N Z \mathrm{~J}$ Obstet Gynaecol 2010:50:36-9.

28 Gilstrap LC 3rd, Hauth JC, Hankins GD, Patterson AR. Effect of type of anesthesia on blood loss at cesarean section. Obstet Gynecol 1987;69:328-32.

29 Combs CA, Murphy EL, Laros RK Jr. Factors associated with hemorrhage in cesarean deliveries. Obstet Gynecol 1991;77:77-82.

30 King KJ, Douglas MJ, Unger W, Wong A, King RA. Five unit bolus oxytocin at cesarean delivery in women at risk of atony: a randomized, double-blind, controlled trial. Anesth Analg 2010;111:1460-6.

31 Magann EF, Evans S, Hutchinson M, Collins R, Lanneau G, Morrison JC. Postpartum hemorrhage after cesarean delivery: an analysis of risk factors. South Med $J$ 2005;98:681-5.

32 Kolas T, Oian P, Skjeldestad FE. Risks for peroperative excessive blood loss in cesarean delivery. Acta Obstet Gynecol Scand 2010;89:658-63.

33 Knight M, Callaghan WM, Berg C, Alexander S, Bouvier-Colle MH, Ford JB, et al. Trends in postpartum hemorrhage in high resource countries: a review and recommendations from the International Postpartum Hemorrhage Collaborative Group. BMC Pregnancy Childbirth 2009;9:55.

Accepted: 3 June 2011 


\section{What is already known on this topic}

Routine use of oxytocin reduces postpartum haemorrhage after vaginal birth, but the effects at caesarean section have received little attention

\section{What this study adds}

Use of an oxytocin bolus and infusion after caesarean delivery reduces the need for additional uterotonic agents but does not reduce overall occurrence of major obstetric haemorrhage

Side effects were not increased after use of an additional oxytocin infusion 


\section{Tables}

\section{Table 1| Baseline characteristics and operative variables of trial participants}

Bolus and infusion

( $n=1033$, unless stated otherwise)

Mean maternal age, years (SD)

Maternal age $\geq 35$ years

Mean BMI (SD)*

Overweight (BMI 25.0-29.9) $\dagger$

Obese (BMI $\geq 30.0) \dagger$

Chronic medical disorderł

Cigarette smoker

Alcohol (moderate/heavy)

Parity $\geq 2$

Previous caesarean section

Previous caesarean sections $\geq 2$

Previous PPH (>500 mL)

Previous pelvic surgery

Mean preop haemoglobin, g/L (SD)

Preop haemoglobin <105 g/L

Mean preop packed cell volume (SD)

Gestational age $\geq 39$ weeks

Infant sex male

Birth weight $\geq 4.0 \mathrm{~kg}$

Junior obstetrician

Junior anaesthetist $\rrbracket^{\star *}$

Vascular lower segment

Scarring/adhesions

Surgical protocol adherence

\begin{tabular}{|c|c|}
\hline $33.2(4.9)$ & $33.2(4.9)$ \\
\hline 423 (40.9) & $431(42.0)$ \\
\hline $26.6(5.4)$ & $26.2(5.0)$ \\
\hline 305 (29.6) & $338(33.0)$ \\
\hline $241(23.4)$ & $210(20.5)$ \\
\hline $137(13.3)$ & $126(12.3)$ \\
\hline $92(8.9)$ & $105(10.2)$ \\
\hline $57(5.5)$ & $57(506)$ \\
\hline 338 (32.7) & 330 (32.2) \\
\hline $678(65.6)$ & 668 (65.2) \\
\hline $218(21.1)$ & $234(22.8)$ \\
\hline $10(1.0)$ & $9(0.9)$ \\
\hline $46(4.5)$ & $44(4.3)$ \\
\hline $117.5(12.2)$ & $117.2(12.2)$ \\
\hline 147 (14.3) & $155(15.2)$ \\
\hline $0.351(0.032)$ & $0.351(0.032)$ \\
\hline 754 (73.0) & $689(67.2)$ \\
\hline $553(53.5)$ & 559 (54.5) \\
\hline $191(18.5)$ & $160(15.6)$ \\
\hline 453 (43.9) & $413(40.3)$ \\
\hline $463(44.9)$ & $452(44.1)$ \\
\hline $14(1.4)$ & $11(1.1)$ \\
\hline $96(9.3)$ & $92(9.0)$ \\
\hline 793 (76.8) & 827 (80.7) \\
\hline
\end{tabular}

Data are number (\%) unless stated otherwise. Percentages refer to completed responses. PPH=postpartum haemorrhage. Preop=preoperation.

*Body mass index: weight $(\mathrm{kg})$ divided by the square of height $(\mathrm{m})$.

†Bolus and infusion: $n=1029$. Bolus only: $n=1023$.

‡Diabetes, endocrine disease, cardiac disease, hypertension, renal disease, inflammatory bowel disease.

$\S$ Bolus and infusion: $n=1031$. Bolus only: $n=1022$.

I Junior grade: $\geq 3$ years of specialist training

${ }^{* *}$ Bolus and infusion: $\mathrm{n}=1032$. 
Table 2| Primary outcomes

\begin{tabular}{|c|c|c|c|c|c|}
\hline & $\begin{array}{c}\text { Bolus and infusion } \\
\text { No (\%) }\end{array}$ & $\begin{array}{c}\text { Bolus only } \\
\text { No (\%) }\end{array}$ & $\begin{array}{l}\text { Adjusted odds ratio* } \\
\qquad(95 \% \mathrm{Cl})\end{array}$ & $P$ value & $\begin{array}{l}\text { Number needed to treat } \\
\qquad(95 \% \mathrm{Cl})\end{array}$ \\
\hline $\begin{array}{l}\text { Major obstetric } \\
\text { haemorrhage (blood loss } \\
>1000 \mathrm{~mL}) \dagger\end{array}$ & $158 / 1007(15.7)$ & 159/994 (16.0) & $0.98(0.77$ to 1.25$)$ & 0.86 & - \\
\hline $\begin{array}{l}\text { Additional uterotonic } \\
\text { agent } \ddagger\end{array}$ & 126/1033 (12.2) & 189/1025 (18.4) & 0.61 (0.48 to 0.78$)$ & $<0.001$ & 16 (11 to 32$)$ \\
\hline
\end{tabular}

*Odds ratios calculated from models adjusted for centre and previous caesarean section.

†Blood loss calculation: estimated blood volume $\times$ (preop PCV - postop PCV)/preop PCV (where PCV=packed cell volume, estimated blood volume=booking weight $(\mathrm{kg}) \times 85)$.

‡Oxytocin infusion, oxytocin bolus, misoprostol, 15-methyl-prostaglandin F2a, syntometrine, or ergometrine. 


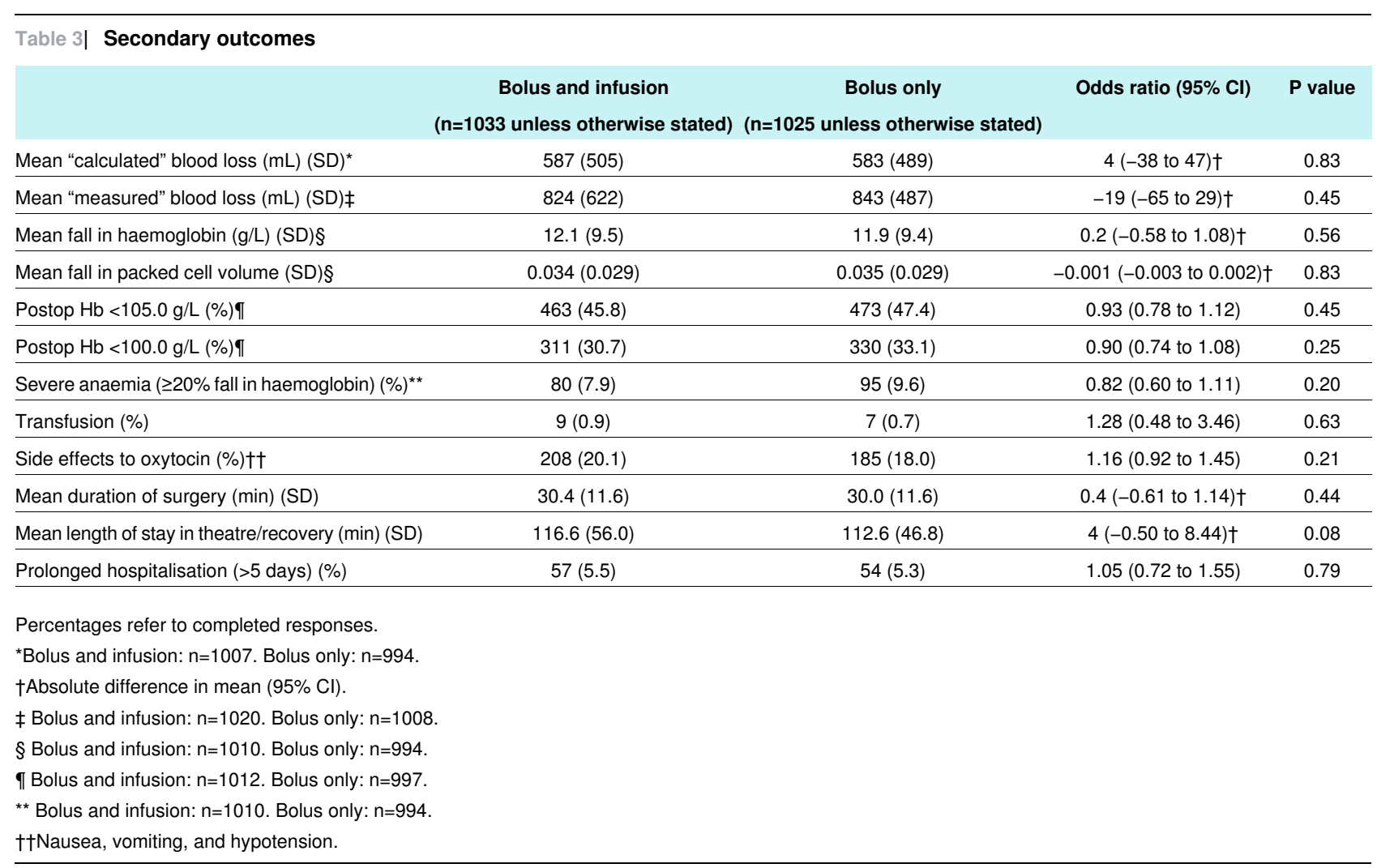




\begin{tabular}{|c|c|c|c|c|c|c|c|c|c|c|c|c|c|c|}
\hline \multicolumn{15}{|c|}{$\begin{array}{l}\text { Table } 4 \text { Subgroup analyses of major obstetric haemorrhage (MOH) and additional uterotonic agent } \\
\text { Adherence to Non-adherence }\end{array}$} \\
\hline & \multicolumn{2}{|c|}{$\begin{array}{c}\text { Junior } \\
\text { obstetrician }\end{array}$} & \multicolumn{2}{|c|}{$\begin{array}{c}\text { Senior } \\
\text { obstetrician }\end{array}$} & \multicolumn{2}{|c|}{$\begin{array}{l}\text { Adherence to } \\
\text { anaesthetic } \\
\text { protocol }\end{array}$} & \multicolumn{2}{|c|}{$\begin{array}{c}\text { Non-adherence } \\
\text { to anaesthetic } \\
\text { protocol }\end{array}$} & \multicolumn{2}{|c|}{0} & \multicolumn{2}{|c|}{1} & \multicolumn{2}{|c|}{$\geq 2$} \\
\hline & Yes & No & Yes & No & Yes & No & Yes & No & Yes & No & Yes & No & Yes & No \\
\hline \multicolumn{15}{|l|}{ MOH } \\
\hline $\begin{array}{l}\text { Bolus and } \\
\text { infusion }\end{array}$ & $\begin{array}{c}76 \\
(17.3) \\
\end{array}$ & $\begin{array}{c}363 \\
(82.7) \\
\end{array}$ & $\begin{array}{c}82 \\
(14.4)\end{array}$ & $\begin{array}{c}486 \\
(85.6) \\
\end{array}$ & $\begin{array}{c}156 \\
(15.7) \\
\end{array}$ & $\begin{array}{c}837 \\
(84.3) \\
\end{array}$ & $2(15.4)$ & $\begin{array}{c}11 \\
(84.6) \\
\end{array}$ & $\begin{array}{c}65 \\
(19.0) \\
\end{array}$ & $\begin{array}{c}278 \\
(81.0) \\
\end{array}$ & $\begin{array}{c}63 \\
(14.0) \\
\end{array}$ & $\begin{array}{c}388 \\
(86.0) \\
\end{array}$ & $\begin{array}{c}30 \\
(14.1) \\
\end{array}$ & $\begin{array}{c}183 \\
(85.9) \\
\end{array}$ \\
\hline $\begin{array}{l}\text { Bolus } \\
\text { only }\end{array}$ & $\begin{array}{c}88 \\
(22.2) \\
\end{array}$ & $\begin{array}{c}308 \\
(77.8)\end{array}$ & $\begin{array}{c}71 \\
(11.9)\end{array}$ & $\begin{array}{c}527 \\
(88.1) \\
\end{array}$ & $\begin{array}{c}155 \\
(15.9)\end{array}$ & $\begin{array}{c}819 \\
(84.1)\end{array}$ & $4(20.0)$ & $\begin{array}{c}16 \\
(80.0)\end{array}$ & $\begin{array}{c}58 \\
(16.7) \\
\end{array}$ & $\begin{array}{c}290 \\
(83.3)\end{array}$ & $\begin{array}{c}65 \\
(15.6)\end{array}$ & $\begin{array}{c}353 \\
(84.4)\end{array}$ & $\begin{array}{c}36 \\
(15.8) \\
\end{array}$ & $\begin{array}{c}192 \\
(84.2)\end{array}$ \\
\hline $\begin{array}{l}\text { OR, } 95 \% \\
\mathrm{Cl}, \mathrm{P} \\
\text { value }\end{array}$ & \multicolumn{4}{|c|}{$0.57,0.35$ to $0.92, P=0.02$} & \multicolumn{4}{|c|}{$1.59,0.24$ to $10.48, P=0.63$} & \multicolumn{6}{|c|}{$0.86,0.62$ to $1.18, P=0.35$} \\
\hline \multicolumn{15}{|c|}{ Additional uterotonic drug used } \\
\hline $\begin{array}{l}\text { Bolus and } \\
\text { infusion }\end{array}$ & $\begin{array}{c}56 \\
(12.4) \\
\end{array}$ & $\begin{array}{c}397 \\
(87.6) \\
\end{array}$ & $\begin{array}{c}70 \\
(12.1) \\
\end{array}$ & $\begin{array}{c}510 \\
(87.9) \\
\end{array}$ & $\begin{array}{c}124 \\
(12.2) \\
\end{array}$ & $\begin{array}{c}895 \\
(87.8) \\
\end{array}$ & $2(15.4)$ & $\begin{array}{c}11 \\
(84.6) \\
\end{array}$ & $\begin{array}{c}52 \\
(14.6) \\
\end{array}$ & $\begin{array}{c}303 \\
(85.4) \\
\end{array}$ & $\begin{array}{c}48 \\
(10.4) \\
\end{array}$ & $\begin{array}{c}412 \\
(89.6) \\
\end{array}$ & $\begin{array}{c}26 \\
(11.9) \\
\end{array}$ & $\begin{array}{c}192 \\
(88.1) \\
\end{array}$ \\
\hline $\begin{array}{l}\text { Bolus } \\
\text { only }\end{array}$ & $\begin{array}{c}80 \\
(19.4)\end{array}$ & $\begin{array}{c}333 \\
(80.6) \\
\end{array}$ & $\begin{array}{c}109 \\
(17.8) \\
\end{array}$ & $\begin{array}{c}503 \\
(82.2) \\
\end{array}$ & $\begin{array}{c}183 \\
(18.2) \\
\end{array}$ & $\begin{array}{c}821 \\
(81.8) \\
\end{array}$ & $6(28.6)$ & $\begin{array}{c}15 \\
(71.4) \\
\end{array}$ & $\begin{array}{c}63 \\
(17.6) \\
\end{array}$ & $\begin{array}{c}294 \\
(82.4) \\
\end{array}$ & $\begin{array}{c}72 \\
(16.6)\end{array}$ & $\begin{array}{c}362 \\
(83.4) \\
\end{array}$ & $\begin{array}{c}54 \\
(23.1) \\
\end{array}$ & $\begin{array}{c}180 \\
(76.9) \\
\end{array}$ \\
\hline $\begin{array}{l}\mathrm{OR}, 95 \% \\
\mathrm{Cl}, \mathrm{P} \\
\text { value }\end{array}$ & \multicolumn{4}{|c|}{$0.95,0.58$ to $1.56, P=0.84$} & \multicolumn{4}{|c|}{$1.40,0.23$ to $8.55, P=0.71$} & \multicolumn{6}{|c|}{$0.76,0.55$ to $1.05, P=0.10$} \\
\hline
\end{tabular}




\section{Figure}

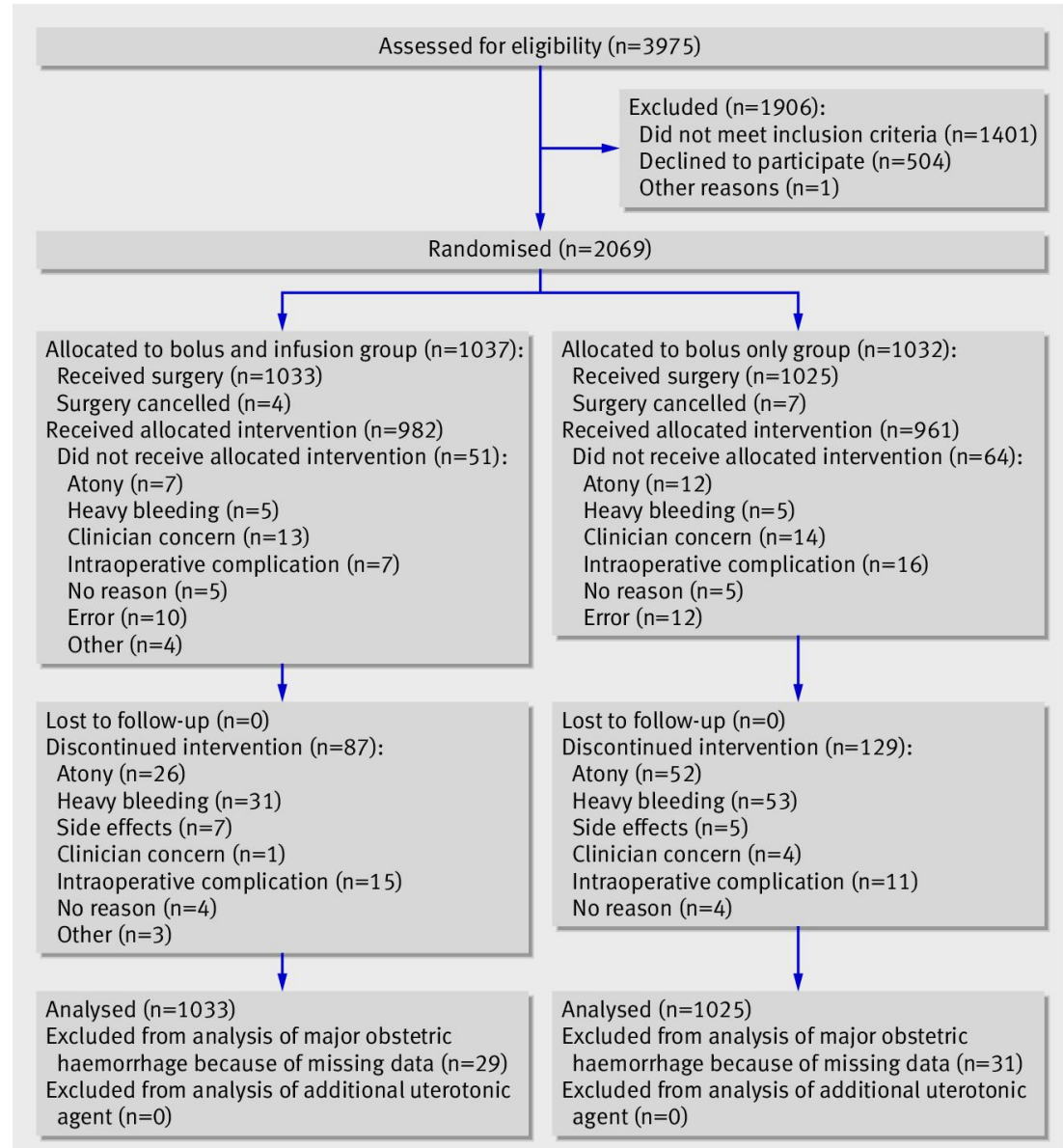

Fig 1 Summary of participant flow through trial 